REFERENCE:

1. Nan L, Wang P, Thumboo J, Lim YW, Vrijhoef HJM. Pharmacoeconomics 2014;32(5):495-507.

Disclosure of Interest: None declared

DOI: 10.1136/annrheumdis-2018-eular.4487

\section{FRI0624 MUSCULOSKELETAL PROBLEMS AMONGST TRAIN OPERATORS: A COLLABORATIVE APPROACH TO IDENTIFY SOLUTIONS}

J. Erwin ${ }^{1}$, J. Howarth ${ }^{1}$, L. Chauhan ${ }^{2}$, A. Webster ${ }^{2}$, A. Woolf ${ }^{1} .{ }^{1}$ Research Development \& Innovation, Royal Cornwall Hospitals NHS Trust, Truro, ${ }^{2}$ Occupational Health, TfL, London, United Kingdom

Background: Transport for London (TfL) Occupational Health Dept identified musculoskeletal (MSK) problems as matters of concern in train operating staff on 3 of the underground lines (JNP). These issues were contentious and the subject of continued discussion between the management of TfL, train operators, Unions and other stakeholders. The Bone and Joint Research Group (BJRG) were invited to undertake work to provide insight into the MSK health issues of train operators from a neutral perspective.

Objectives: To assess the problems and issues relating to the musculoskeletal health of train operators.

Methods: A steering committee was created with representatives from the train operators, the Unions, TfL managers and other stakeholders. Participants were recruited to 6 focus groups. Separate focus groups were held for operators, managers and for other stakeholders. The groups were asked to discuss the status of their own MSK health, the impact of work on their MSK health, the support they receive from their employer and others, barriers and facilitators to maintaining MSK health, the role of managers in improving MSK health in the workplace and what interventions would improve MSK health.

The focus groups were recorded transcribed and analysed using Thematic Analysis.

The findings informed a survey of JNP train operators. The survey was co-produced and endorsed by the BJRG, TfL and the Unions and circulated to train operators. The survey included questions on demographics, lifestyle, work role, posture training, MSK problems, actions taken and ideas on how MSK risks could be managed and MSK health protected and improved.

Results: $20 \%$ of train operators (338) completed the survey. Respondents reflected the demographic profile of the total JNP train operators. $72 \%$ reported not receiving adequate posture training. $74 \%$ experienced MSK pain, either currently or in the past. Of these $52 \%$ were currently in pain. The average number of months in pain was 59. Lower back, neck and shoulders were the most frequently reported sites of pain. $74 \%$ said the pain was caused by or worsened by work. An average of 7 days of work was lost per year due to MSK problems. $44 \%$ had not told their manager. Most respondents said their MSK health could be improved by improvements to their seating and cab ergonomics.

Participants acknowledged that it is an individual's responsibility to look after their own MSK health and suggested ways to do this. These included changing position when driving, stretching, improved posture, employing good manual handling techniques, exercising outside of work and eating healthily.

Conclusions: MSK problems are a significant issue among JNP train operators and structural problems are perceived to be the main cause. Operators are aware of their own role in maintaining their MSK health both at work and at home. The study illustrates that it is possible to work effectively and collaboratively with a range of workplace stakeholders to achieve a common goal of improved MSK health. The active involvement of all stakeholders throughout the process and the engagement of a neutral research organisation increased "buy-in" and gave credibility to the project. The findings are currently being considered by the steering committee to produce a series of recommendations at the policy, operational and individual level to protect the MSK health of train operators.

Disclosure of Interest: None declared

DOI: 10.1136/annrheumdis-2018-eular.6875

\section{FRI0625}

DIFFERENT STRATEGIES TO IMPLEMENT THE EULAR GUIDELINE FOR CARDIOVASCULAR RISK MANAGEMENT IN DAILY PRACTICE

J. Weijers ${ }^{1}$, P. Dessein ${ }^{2}$, D. Galarza-Delgado ${ }^{3}$, M. González-Gay ${ }^{4}$, B. Kuriya ${ }^{5}$, E. Myasoedova ${ }^{6}$, A. Semb ${ }^{7}$, S. Wållberg-Jonsson ${ }^{8}$, P. van Riel ${ }^{1,9}$ on behalf of Trans-Atlantic Cardiovascular Consortium for Rheumatoid Arthritis (ATACC-RA). ${ }^{1}$ IQ healthcare, Scientific Center for Quality of Healthcare, Radboud university medical center, Nijmegen, Netherlands, ${ }^{2}$ Rheumatology Division, Universitair Ziekenhuis and Vrije Universiteit, Brussels, Belgium, ${ }^{3}$ Department of Rheumatology, University of Nuevo Leon, Medicine School and University Hospital, Mexico, San Nicolás de los Garza, Mexico, ${ }^{4}$ Division of Rheumatology, Hospital Universitario Marques de Valdecilla, Santander (Cantabria), Spain, ${ }^{5}$ Division of Rheumatology, Department of Medicine, Faculty of Medicine, University of Toronto, Toronto, Canada, ${ }^{6}$ Division of Rheumatology, Department of Internal Medicine, Mayo Clinic, Rochester, MN, United States, ${ }^{7}$ Preventive CardioRheuma Clinic, Department of Rheumatology, Diakonhjemmet Hospital, Oslo, Norway, ${ }^{8}$ Department of Public Health and Clinical Medicine/Rheumatology, University of Umeå, Umeå, Sweden, ${ }^{9}$ Rheumatology, Bernhoven, Uden, Netherlands

Background: The updated EULAR cardiovascular risk management (CVRM) guideline recommends cardiovascular disease risk assessment at least once every five years in all patients with rheumatoid arthritis (RA). ${ }^{1} \mathrm{~A}$ literature search indicates that this guideline is marginally applied in clinical practice. ${ }^{2} \mathrm{An}$ important factor explaining dissimilarities in the quality of CVRM could be the different strategies being used to implement this guideline in daily care.

Objectives: This study describes the differences in cardiovascular risk identification and management for patients with RA between outpatient clinics of the members of the Trans-Atlantic Cardiovascular Consortium for Rheumatoid Arthritis (ATACC-RA).

Methods: A questionnaire was sent to all members of ATACC-RA, which included 16 questions about 'the organisation and responsibility of CVRM in their hospital', 'the screening of cardiovascular risk factors', 'communication about CVRM between medical professionals' and 'availability of data regarding CVRM'. Results: Six out of eight outpatient clinics reported that they work according the EULAR CVRM recommendations. Three strategies to organise CVRM in daily practice could be distinguished: 1) The treating rheumatologist performs CVRM during the outpatient visits; 2) Cardiologists, rheumatologists and/or a general practitioners co-operate in a cardio-rheuma-clinic/team with different tasks and responsibilities and 3 ) the general practitioner screens and treats cardiovascular risk factors. Six outpatient clinics reported that they have (digital) data about the current CVRM status of their RA patients and are willing to share them to compare the quality of the CVRM care between the different strategies.

Conclusions: Each cardiovascular risk management strategy was based on agreements between medical professionals about who is responsible to perform CVRM. However, each strategy is also (partly) dependent of the national healthcare system and financial resources. Independent of how CVRM is organised, communication and feedback between medical professionals about the current CVRM status of each RA patient, are important factors to perform CVRM adequately. Further analyses on the effectiveness of the various systems are warranted.

\section{REFERENCES:}

1. Agca R, Heslinga SC, Rollefstad S, et al. EULAR recommendations for cardiovascular disease risk management in patients with rheumatoid arthritis and other forms of inflammatory joint disorders: 2015/2016 update. Annals of the rheumatic diseases 2016. doi:10.1136/annrheumdis-2016209775

2. Weijers JM, Rongen-van Dartel SAA, Hoevenaars DMGMF, et al. Implementation of the EULAR cardiovascular risk management guideline in patients with rheumatoid arthritis: results of a successful collaboration between primary and secondary care. Annals of the rheumatic diseases 2017. doi:10.1136/annrheumdis-2017-212392

Disclosure of Interest: None declared DOI: 10.1136/annrheumdis-2018-eular.5216 